\title{
REPLICA PLATE SCREENING METHOD FOR DETECTING PHOSPHATASE ACTIVITY IN BASIDIOMYCETES USING 1-NAPTHYL PHOSPHATE AS A CHROMOGENIC SUBSTRATE
}

\author{
*JAYA PRAKASH GOUD, M; VINAYA SAGAR GOUD, J; SINGARA CHARYA, M. A.
}

\author{
Department of Microbiology, \\ Kakatiya University, Warangal, 506009-A.P, India \\ *(Corresponding author) \\ jp_muthyala@yahoo.co.in
}

\begin{abstract}
A chromogenic substrate depended replica plate assay that can be used to screen phosphatase activity in basidiomycetes is described. 1-napthyl phosphate can be incorporated directly into the agar plates used to culture the organisms of interest. The approach offers several advantages over current methodologies including the ability to monitor the development of phosphatase activity with colony development, and the ability to distinguish between activity arising from cell-bound and cell-free enzyme. Phosphatase activity was confrrmed by staining the replica plate with fast blue RR salt. This enzyme probe was successfully used to detect phosphatase producing basidiomycetes.
\end{abstract}

KEY WORDS: Phosphatase activity, Basidiomycetes, 1-napthyl phosphate, Fast Blue RR

\section{INTRODUCTION}

Phosphorus is a major essential macro element required by plants to grow and develop. It is mostly deficient in soils as it is fixed as water insoluble iron and aluminium phosphates in acidic soils or calcium phosphate in alkaline soils (Singh \& Kapoor 1994). Chemical phosphatic fertilizers are only sparingly soluble under the conditions in which they are applied to the soil. However, under such conditions microorganisms offer a biological rescue capability of solubilizing the insoluble inorganic phosphorus of soil. Phosphate solubilizing microorganisms (PSM) include largely bacteria and fungi, which can grow on various phosphorus containing compounds. Such microbes not only accumulate $\mathrm{P}$ but a large portion of soluble phosphate is released in excess of their own requirement. Microorganisms have been found to solubilize the low soluble calcium phosphate via the production of exo-metabolites (phosphatases) and make them available to plants (Rao 2000).The use of biofertilizers or microbial inoculants for replacing the efficacy of chemical fertilizers has been found to be effective in reducing the cost of cultivation and maintaining the natural fertility of soil (Gothwal et al. 2006).

Most of the research on phosphatase has been directed at the characterization, production and application of rhizosphere microorganisms, while many possible sources of novel phosphatases remain unexplored. The present paper discusses a rapid screening replica plate assay method for screening phosphatase producing basidiomycetes.

\section{MATERIALS AND METHODS}

Chemicals: 1-napthyl phosphate, Fast blue RR and Ammonium vanadate were purchased from Sigma Chemical Co. (St. Louis MO, USA). Cobalt chloride, Ammonium molybdate (SD fine chemicals), agar (High media, Mumbai) and all other chemicals (Merck/qualigens) were purchased commercially at the highest purity possible.

Organisms and media: Four basidiomycetous fungi Gomophus clavitus, Pycnoporus coccinus, Craterillus cornucopoides and Oligoporus phytogaster were obtained from the Microbial Collection Laboratory, Department of Microbiology, K. U. India.
Pure cultures were maintained on basal media made of glucose $5 \mathrm{~g}$, $\mathrm{KNO}_{3} 3.5 \mathrm{~g}, \mathrm{KH}_{2} \mathrm{PO}_{4} 1.75, \mathrm{MgSO}_{4} 0.75 \mathrm{~g}$, agar-agar $16 \mathrm{~g}$ per litre of distilled water. For phosphate solubilization studies, glucose in the basal media was replased by a-napthyl phosphate $(0.8 \mathrm{~g} / \mathrm{l})$.

Preparation of experimental plates: $20 \mathrm{ml}$ of the medium was poured into petri plates and allowed to solidify. With a sterile agar borer, $6 \mathrm{~mm}$ bores were prepared and replaced with 5 days old fungal culture. Plates were prepared in triplicates for each medium and for each individual fungi, sealed with paraffin tape and incubated for 4 days at $28{ }^{\circ} \mathrm{C}$. The development of halos and mycelium around each inoculum was observed every $12 \mathrm{hr}$.

Plate staining: Following growth, one set of petri plates was flooded with a $2 \%(\mathrm{w} / \mathrm{v})$ aqueous cobalt chloride solution. After a $5 \mathrm{~min}$ incubation at room temperature, the cobalt chloride solution was replaced with a freshly prepared solution containing equal volumes of a $6.25 \%(\mathrm{w} / \mathrm{v})$ aqueous ammonium molybdate solution and $0.42 \%$ (w/v) ammonium vavadate solution. Following a 5 min incubation, the ammonium molybdate/ammonium vanadate solution was removed and the plates examined for zones of clearing. Another set of petri plates (replica plates) were overlaid with freshly prepared solution of fast blue RR salt (0.25\% in $10 \mathrm{~m} \mathrm{M} \mathrm{Tris-Hcl} \mathrm{buffer} \mathrm{PH} 7.5)$ for 10 min. Excess stain was removed from the plate and washed with $7 \%$ acetic acid. All the plates were photographed and documented (Plate 1).

\section{RESULTS}

Phosphatase activity was identified by a distinct zone of clearing around fungal colony. Maximum zone of clearance was observed with Gomophus clavitus (26mm) followed by Pycnoporus coccinus (23mm) and Craterellus cornucopoides $(21 \mathrm{~mm})$. No zone of clearance was observed with Oligoporus ptychogaster (Plate 1A). Appearance of transparent yellow halos around the colonies is the result of phosphatase activity. Cobalt chloride reacts with phosphates to form a complex in pink colour. Effect of incubation on phosphatase activity was studied and the activity increased with the colony development. Growth activity was not recorded in Oligoporus phytogaster but only in the other 3 fungal species studied. Plate 1B showed the replica plates stained with Fast blue RR. 


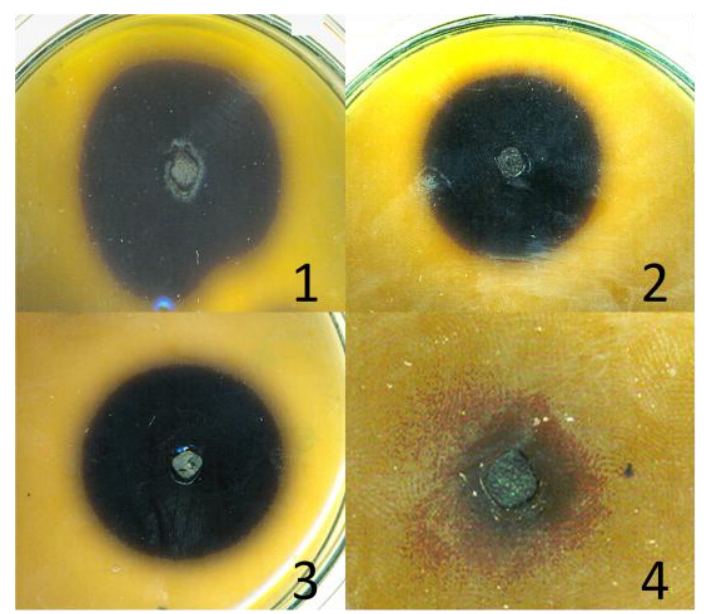

A

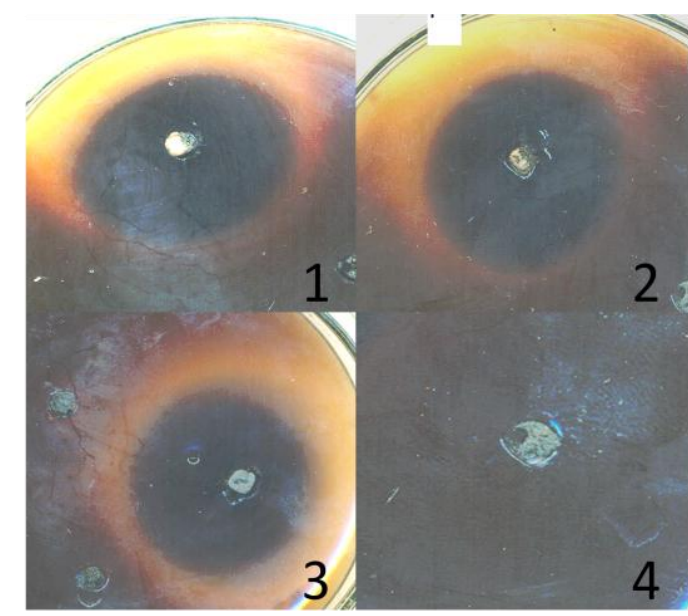

B

PLATE 1: SCREENING FOR PHOSPHATASE PRODUCING BASIDIOMYCETES
1- Gomophus clavitus
3- Craterillus cornucopoides
2- Pycnoporus coccinus
4- Oligoporus phytogaster

\section{NOTES:}

A: Agar plates with 1-naphthylphosphate $(0.8 \mathrm{~g} / \mathrm{l})$ as a chromogenic substrate (Ammonium molybdate/Ammonium vanadate staining)

\section{B: Agar plates with 1-naphthylacetate $(0.8 \mathrm{~g} / \mathrm{l})$ as a chromogenic substrate (Fast blue rr staining)}

\section{DISCUSSION}

When searching complex microbial communities for novel enzymatic phenotypes, it is useful to have the ability to rapidly screen large numbers of isolates. Current methods for screening large numbers of microorganisms for phosphate activity rely heavily on the use of colorimetric assays. While such methods have been applied extensively in the laboratory, they are not without their drawbacks.

In this study, we used a modification of the differential phytase screening medium reported by Howson \& Davis (1983). Phosphate solubilizing microorganisms (PSM) include bacteria and fungi, which can grow on various phosphorus containing compounds (Rodriguez \& Fraga 1999). Even though Cobalt chloride reacts with phosphates to form a complex in pink colour, the precise mechanism involved in the counterstaining is not clearly defined but the addition of molybdate/vandate solution changes the colour from pink to yellow and enhances the contrast (Bae et al. 1999). Effect of incubation on phosphatase activity showed the activity to increase with the colony development. Similar observation was made by Van et al. (1999) between phosphatase activity and the incubation period. The black zone observed around the fungal inoculums (Plates $1 \mathrm{~A} \& 1 \mathrm{~B}$ ) is due to growth of mycelium. Except Oligoporus phytogaster, the other three fungal species exhibited growth indicating the hydrolysis and utilization of 1- napthyl phosphate as a growth substrate as a result of phosphatase activity.

The zones of clearance in counter staining plates are highly depended on the concentration of metal cations used and the time of staining. Most times, the hallo zones of clearance are not easily detectable unless there is a strong activity (data not provided) which necessitates the need for staining napthol deposition. The alpha napthyl subatrates are hydrolysed by enzymatic action to alpha napthol (Miller \& Karn 1980). The liberated alpha napthol couples to fast blue RR salt to form a diazo complex in brown colour (Kim 2002) which is a positive indication of phosphatase activity. Except Oligoporus ptychogaster, the remaing 3 fungal species studied (Gomophus clavitus, Pycnoporus coccinus and Craterillus cornucopoides) all showed a brown holo zone due to coupling of fast blue RR with the napthol diposition as a result of phosphatase activity. Parallel to the results from the counterstainig plate, 1-napthyl phosphate in the remaining part of the plates and the plate containing Oligoporus ptychogaster as a whole have become dark. This is due to unavailability of liberated napthol for fast blue RR to form a complex in the replica plates due to absence of phosphatase activity (Compare the plates in A (1-4) with B (1-4). Staining for napthol deposition is for confirmation of the Phosphate solubilizing efficiency (PSE) of the basidiomycetes and for authenticity of the results from the counter staining. PSE in the replica plates were similar to that in the counter stained plate. Advantage of this method over calorimetric assays is the ability to distinguish between activity arising from cellbound and cell-free enzyme.

Results of the studies on the influence of added nutrients (glucose) on phosphatase activity showed increase in enzyme activity with increase in glucose concentration. This method can also be used to study the effect of overlapping substrate on phosphatase activity (However, this was depended on fungal species). This method is highly reproducible and non specific, but class 1 inhibitors can be incorporated into agar plates to resolve the characteristics of the enzyme. Non specific phosphatase chromogenic substrates may be used to identify phytase 
activities (Van et al. 1993) and the influence of various environmental factors like ph and temperature can be checked with reliability.

It is concluded that the PSE of the basidiomycetes studied exhibiting positive activities can be of value in using basidiomycetes as phosphate solubilizers. This method can also be modified to screen microorganisms including bacteria and lower fungi, which produces phosphatases normally in low quantities. Since the screening of a large number of microbes for phosphatases by replica plate assay as discussed above is time saving, this approach can also be used to construct metagenomic libraries. Thus, this replica plate staining method using 1-napthyl phosphate as a chromogenic substrate may have useful application in screening for phosphatase activity in basidiomycetes on solid medium.

\section{ACKNOWLEDGEMENT}

We thank Professor V. Laxmipathi, Enzymology Laboratory, Kakatiya University, Warangal, India for developing the protocol. We are grateful to professor S. ram Reddy, Head, Department of Microbiology, KKU for facilities and Mr. P. Chaeralu for technical assistance

\section{REFERENCES}

Bae, H. D., Yanke, L. J., Cheng, K. J. \& Selinger, L. B. A. 1999. Novel staining method for detecting phytase activity. Journal of Microbiological Methods. 39: 17-22

Gothwal, R, K., Nigam, V. K., Mohn, M. K., Saspaal, D. \& Ghosh, P. 2006. Phosphate solubilization by rhizosphere bacterial isolates from economically important desert plants. Indian journal of microbiology. 46: 355-358.

Howson, S. J. \& Davis, R. P. 1983. Production of phytate-hydrolysing enzyme by some fungi. Enzyme and Microbiol Technology. 5: 377383.
Kim, J. Y., Cho, G. S., Kim, Y. J., Ryu, Y. W. \& Kim, G. J. 2002. A new isolate Bacillus stearothermophilus JY144 expressing a novel esterase with high enantioselectivity to ( $R$ )-ketoprofen ethyl ester: strain selection and gene cloning, Journal of Molecular Catalysis B: Enzymatic. 18: 133-145

Miller, R. B. \& Karn, R. C. 1980. A rapid spectrophotometric method for the determination of esterase activity. Journal of Biochemical and Biophysical Methods. 3:345-354.

Rao, A. V. 2000. Soil biotechnological approaches for sustainable agricultural production in India arid zone, Microbiotech 2000, 41st Annual Conference, Association of Microbiologists of India. pp 6

Rodriguez, H. \& Fraga, R. 1999. Phosphate solubilizing bacteria and theia role in plant growth promotion. Biotechnology Advances. 17: 319-339.

Singh, S. \& Kapoor, K. K. 1994. Solubilization of insoluble phosphate by bacteria isolated from different sources. Environment and Ecology. 12: $51-55$.

Van, H. W., Van, Z. C. M. J., Harteveld, M. G., Gouka, R. J., Suykerbuyk, M. E. G., Luiten, R. G. M., Van, P. P. A., Selten, G. C. M., Veenstra, A. E., Van, G. R. F. M. \& Van, D. H. C. A. M. J. 1993 Cloning, Characterization and Overexpression of the phytase gene (phyA) of Aspergillus niger, Gene, 127: 87-94.

Van, O. K. F., Baty, A. M., Eastburn, C. C., Zhenjun, D. \& Geesey, G. G. 1999. Novel method for screening bacterial colonies for phosphatase activity. Journal of Microbiol Methods. 38: 25-31. 